\title{
TÊMPERA POR INDUÇÃO ELETROMAGNÉTICA APLICADA EM VIRABREQUIM DE MOTOCICLETA
}

\author{
J. G. TENÓRIOA ${ }^{2}$, A. J. VASCONCELOS ${ }^{1}$, I. B. MAGNO ${ }^{1}$, E. F. SOARES ${ }^{1}$ e O. L. ROCHA ${ }^{1 *}$ \\ ${ }^{1}$ Instituto Federal de Educação, Ciência e Tecnologia do Pará - IFPA \\ ${ }^{2}$ Universidade Federal do Pará - UFPA \\ otvrocha@oi.com.br
}

Artigo submetido em março/2015 e aceito em maio/2015

DOI: 10.15628/holos.2015.2917

\section{RESUMO}

Neste trabalho o tratamento térmico de têmpera por indução eletromagnética foi aplicado em virabrequim de motocicleta. Um dispositivo de têmpera por indução eletromagnética do tipo Indutor Reto foi utilizado, cujo calor para aquecer a região a ser temperada é gerado na própria peça. Medição da profundidade da camada temperada, ensaios de metalografia, caraterização por microscopia ótica e difratometria por raios $X(D R X)$ e ensaios de macrodureza (Rockell C - HRC), variando do núcleo à superfície da região temperada, foram realizados. Os resultados obtidos mostram que a profundidade da têmpera alcançou o valor de 1,5 mm e as macrodurezas obtidas, para três virabrequins ensaiados, foram 20, 22 e 23 HRC no núcleo e 54, 54 e 58 HRC na superfície tratada, respectivamente. A microestrutura resultante apresenta no núcleo da peça ferrita pró-eutetóide em rede nos contornos de grãos de perlita toostita. A região tratada termicamente é composta por uma área refinada de carbonetos dispersos em matriz rica em ferrita refinada, resultando numa microestrutura martensita-revenida. A comparação dos resultados experimentais deste trabalho com padrões de qualidade, estabelecidos pelo fabricante da motocicleta, comprovou a eficácia do tratamento térmico superficial aplicado no virabrequim.

PALAVRAS-CHAVE: Têmpera por Indução Eletromagnética, Microscopia Ótica, Difratometria por Raios X (DRX), Dureza.

\section{HARDENING BY ELECTROMAGNETIC INDUCTION APPLIED IN MOTORCYCLE CRANKSHAFT}

\begin{abstract}
In this paper, the heat treatment by electromagnetic induction was applied in motorcycle crankshaft. An electromagnetic induction device of Straight Inductor type has been used, whose heat to warm hardened region is generated on the part itself. Measuring the depth of hardened layer, metallographic tests, optical microscopy and X-rays diffraction (XRD) characterization and hardness tests (Rockell C- HRC), ranging from the core to the surface of the hardened region, were performed. The results show that the depth of hardening has reached the value $1.5 \mathrm{~mm}$, and the hardness observed for the three tested crankshafts were 20,22 e
\end{abstract}

$23 \mathrm{HRC}$ at the core, and 54, 54 e $58 \mathrm{HRC}$ at the treated surface, respectively. The microstructure at the core of the heat treated specimen is composed of pro-eutectoid ferrite network around the grains of toostita perlite. The thermally treated region is composed by an area of fine carbides dispersed in refined ferrite-rich matrix, resulting in a tempered-martensite microstructure. The comparison of the experimental results of this work to quality standards, established by the motorcycle manufacturer, proved the effectiveness of surface heat treatment applied to the crankshaft.

KEYWORDS: Electromagnetic induction hardening, optical microscopy, X-ray diffraction, hardness. 


\section{INTRODUÇÃO}

Os setores industriais de componentes automotivos (aços carbono ou média liga) e o de biomateriais (aços inoxidáveis e ligas especiais) vêm se firmando como grande consumidor da engenharia de superfície, estando em intensa atividade de pesquisa, despertando interesse de pesquisadores no mundo inteiro. Nesses segmentos industriais, destacam-se os processos de endurecimento superficial, dos quais emergem os tratamentos térmicos que visam modificar as principais propriedades físicas e mecânicas dos materiais metálicos, sendo os aços, aqueles que melhor respondem a tais processos. Assim, dependendo do tratamento, esses materiais sofrem transformações estruturais importantes, agregando certas propriedades, as quais são estendidas, normalmente, a distâncias importantes na massa do corpo considerado (RUDNEV et al, 1997, 2003; RUDNEV 2003; RUDNEV, 2004).

A utilização de um ou outro processo é função das propriedades que se deseja obter na superfície. As formas geométricas das peças a serem tratadas, o curto tempo de tratamento, a alta eficiência e a baixa energia consumida no processo, apontam o tratamento térmico por indução eletromagnética particularmente interessante para o endurecimento superficial de partes do motor, como o virabrequim, elemento responsável por transmissão de potência e movimentos para as rodas da motocicleta. Nesse processo, a região tratada sofre apenas um aquecimento a temperaturas superiores à de transformação austenítica ( $\mathrm{A} 3$-diagrama $\mathrm{Fe}-\mathrm{C}$ ), seguido de um resfriamento com velocidades superiores à velocidade crítica.

Apesar da escassez de trabalhos científicos na literatura, o tratamento térmico por indução eletromagnética de materiais é utilizado em campos diversos da engenharia, com forte aplicação na indústria automotiva, principalmente quando se deseja obter alteração das propriedades superficiais de peças metálicas e equipamentos. É sem dúvida um dos mais efetivos processos de tratamento térmico para diversas aplicações, incluindo: têmpera total, têmpera superficial, revenido, alívio de tensões, recozimento, normalização, sinterização de metais, pulverizados e outros (YUAN et al, 1990; FERREIRA, 2004; RUDNEV et al, 1997; DANDA, 2011; MACEDO, 2007; NITKIEWIEZ E JEZIORSKI, 1991; VENKATESH et al, 2009; SAHAA et al, 2010; KANG, et al, 2012; TOTIK et al 2003; BLAOW et al, 2007; FENG et al, 2013; BARKA et al, 2012; BARKA, et al, 2014.).

Na têmpera por indução, a energia necessária é fornecida na forma elétrica. Um conversor fornece corrente alternada de alta frequência para uma bobina (indutor) que induz uma corrente parasita na superfície da peça, aquecendo-a rapidamente. A temperatura depende da potência disponível e do tempo de aquecimento. A Figura 1 apresenta esquematicamente o processo.

Neste trabalho, pretende-se correlacionar parâmetros padrões de tratamento térmico, aplicados na indústria de 2 (duas) rodas, com microestrutura e dureza, para tanto, o virabrequim direito de uma motocicleta de 125 cilindradas foi tratado termicamente por têmpera por indução. O tratamento foi aplicado na própria indústria de fabricação da motocicleta. Um dispositivo de têmpera do tipo Indutor Reto, que promove o tratamento térmico de têmpera por indução magnética de alta frequência, foi utilizado. $O$ calor para aquecer a região a ser temperada é gerado na própria peça, através da indução eletromagnética. 

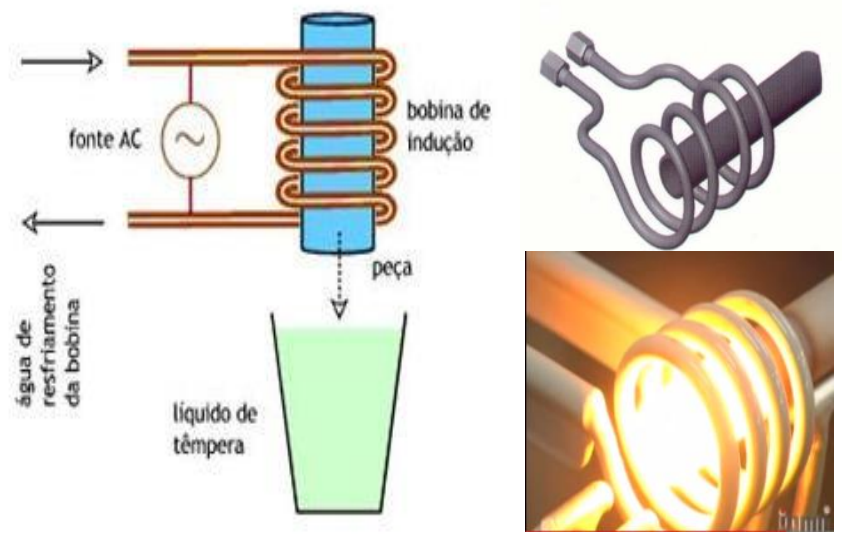

Figura1: Esquema ilustrativo do processo de têmpera por indução (Fonte: http://www.proterm.com.br/ RUDNEV et al, 2003).

\section{PROCEDIMENTO EXPERIMENTAL}

O trabalho consistiu na aplicação do tratamento térmico superficial de têmpera por indução magnética progressiva de alta frequência em três (3) virabrequins (iguais) direito de uma motocicleta, fabricados por forjamento, a partir de lingotes em forma de barras de aço AISI 1045, laminados a quente, desgaseificados, compostos de grãos austeníticos, controlados e fabricados através do método de fundição contínua. A composição química do aço AISI 1045 utilizado neste trabalho se encontra dentro dos valores nominais apresentados na Tabela 1. Ressalta-se que por motivo de segredo industrial não foi possível a publicação da sua composição efetiva.

Tabela 1. Composição química da liga de aço em estudo AISI 10459.

\begin{tabular}{cccccccc}
\hline $\mathbf{C}$ & $\mathbf{S i}$ & $\mathbf{M n}$ & $\mathbf{P}$ & $\mathbf{S}$ & $\mathbf{C u}$ & $\mathbf{N i}$ & $\mathbf{C r}$ \\
\hline 0,45 & 0,15 & 0,60 & 0,030 & 0,015 & 0,30 & 0,25 & 0,10 \\
$\mathrm{a}$ & $\mathrm{a}$ & $\mathrm{a}$ & $\operatorname{Max}$ & $\mathrm{a}$ & $\mathrm{Max}$ & $\mathrm{Max}$ & $\mathrm{a}$ \\
0,51 & 0,30 & 0,90 & & 0,030 & & & 0,20 \\
\hline
\end{tabular}

A Figura 2 mostra uma vista esquemática do virabrequim, cujos detalhes das características dimensionais, para aplicação do tratamento térmico superficial de têmpera por indução magnética, encontram-se apresentados na Tabela 2.

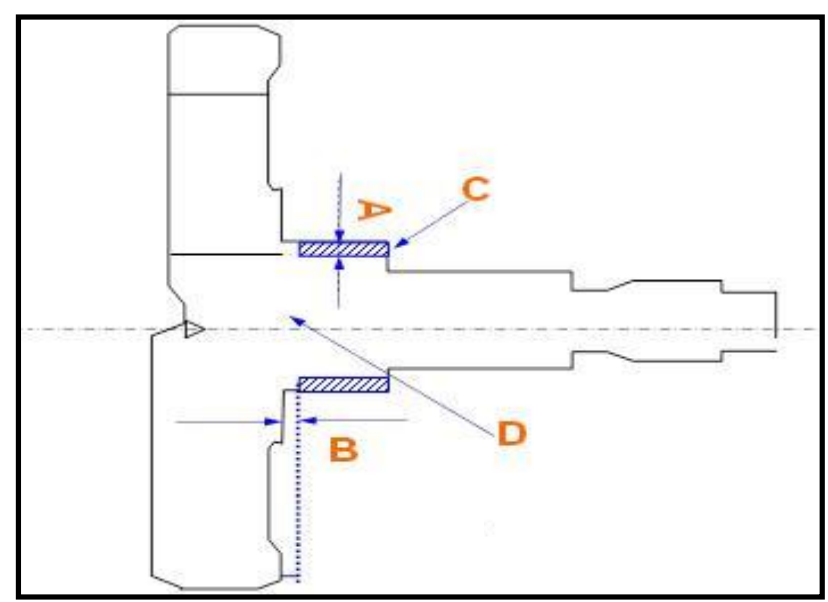

Figura 2. Desenho esquemático do virabrequim, mostrando as características dimensionais da camada endurecida após têmpera. (Fonte: Fabricante da motocicleta). 
Tabela 2: Descrições dimensionais referentes à Figura 2 (Fonte: Fabricante da motocicleta).

\begin{tabular}{ccc}
\hline Item & Descrição & Dimensão \\
\hline A & Profundidade da têmpera $(\mathrm{mm})$ & 0,7 a 3,1 \\
\hline B & Altura onde fica a têmpera $(\mathrm{mm})$ & 2,9 a 4,4 \\
\hline C & Dureza da têmpera $(\mathrm{HRC})$ & 45 a 60 \\
\hline D & Dureza do núcleo $(\mathrm{HRC})$ & 17 a 25 \\
\hline
\end{tabular}

Para o processamento térmico dos virabrequins, foi utilizado um equipamento de indução eletromagnética, fabricado pela empresa Inductotherm Group Brasil, com ajustes e adaptação de projetos realizados pelos técnicos da Inductotherm, validados pelos Engenheiros do Fabricante da Motocicleta. A Figura 3 apresenta um desenho esquemático do equipamento de têmpera utilizado neste trabalho.

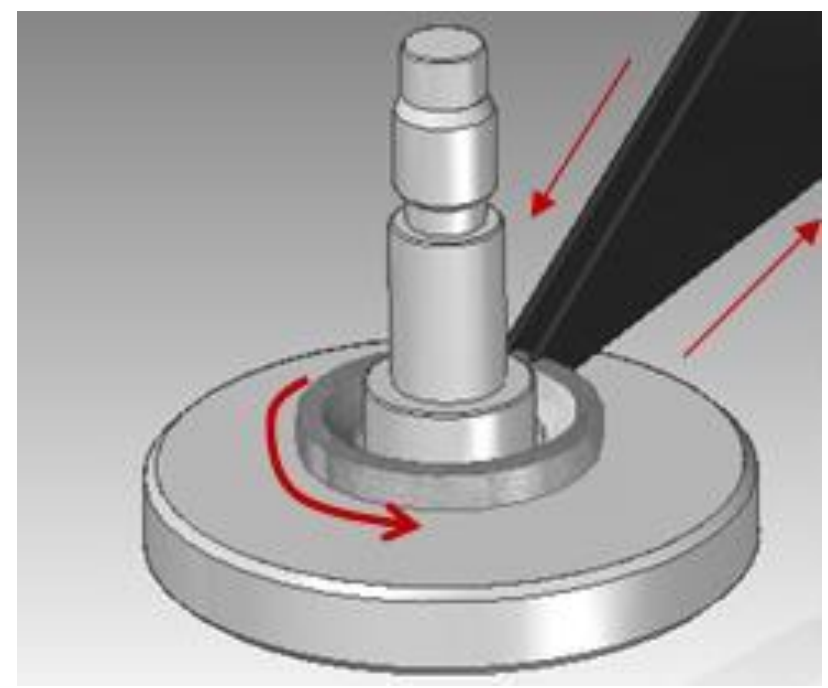

Figura 3. Dispositivo utilizado no processo de têmpera tipo: Indutor Reto com Furo $\varnothing 34 \mathrm{~mm}$ (Mod. Fab. KRM "R" Base: $\emptyset 30,3$ Haste), indicando o virabrequim sendo processado termicamente. (Fonte: Fabricante da motocicleta).

Para o desenvolvimento deste trabalho, três (3) virabrequins foram submetidos ao mesmo tratamento térmico por indução eletromagnética. Executado em dois estágios. O primeiro estágio descreve o processo superficial de têmpera, e o segundo estágio o processo de revenimento para alívio de tensões. As faixas de potência e tempo utilizados foram de $73 \mathrm{~kW}$ a $85 \mathrm{~kW}$ por $2 \mathrm{~s}$ a $4 \mathrm{~s}$ contínuos, para austenitização, e de $39 \mathrm{~kW}$ a $42 \mathrm{~kW}$, por 2s pulsados, para revenimento. Em seguida, realizou-se a correlação entre tratamento térmico, microestrutura e dureza da região tratada termicamente. As temperaturas de austenitização e revenimento foram $1048{ }^{\circ} \mathrm{C}$ e $480{ }^{\circ} \mathrm{C}$, respectivamente. A temperatura do fluido para resfriamento após o aquecimento de austenização foi controlada entre $25^{\circ} \mathrm{C}$ a $35^{\circ} \mathrm{C}$, com pressão da ducha entre $0,5 \mathrm{kgf} / \mathrm{cm}^{2}$ a $1,0 \mathrm{kgf} / \mathrm{cm}^{2}$ e vazão entre 75 LPM a 85 LPM (litros por minuto). No revenimento, o resfriamento foi realizado ao ar livre (temperatura ambiente).

Após o tratamento térmico, os virabrequins foram submetidos a uma operação de limpeza da área tratada termicamente a fim de possibilitar a visualização da região tratada, bem como para checagem das especificações de projeto (Figura 2). Essa operação restringiu-se à limpeza com jato de ar comprimido para retirada do excesso de sujeira, um lixamento da superfície tratada e 
aplicação de ácido Nital 10\% (90 ml de álcool etílico e $10 \mathrm{ml}$ de ácido nítrico concentrado) para destacar a região tratada.

Um durômetro do tipo universal foi utilizado para realização da macrodureza (Rockwell C HRC). A carga utilizada foi de $150 \mathrm{kgf} / \mathrm{cm}^{2}$ e 5 medições de HRC, foram obtidas nas superfícies tratadas, indicadas pela seta vertical e também no núcleo, diretamente de cada virabrequim, considerando-se a média dos valores medidos como resultado final. Os locais de medição estão indicados por setas na Figura 4. As medidas na área tratada (seta vertical) foram realizadas em linha, e no núcleo (seta horizontal) foram obtidas em cruz.

O próximo passo foi medir a profundidade da camada (item A, indicado na Figura 2) endurecida, proveniente do tratamento térmico de têmpera por indução eletromagnética, conforme esquema indicado na Figura 4 (a).

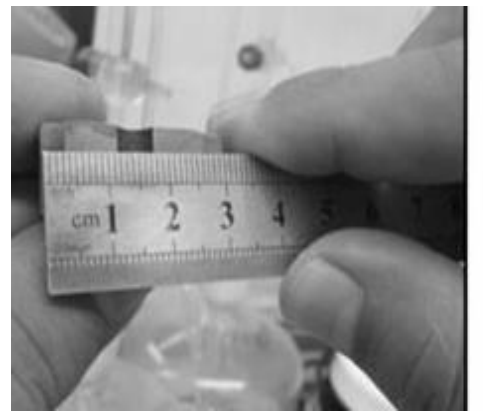

(a)

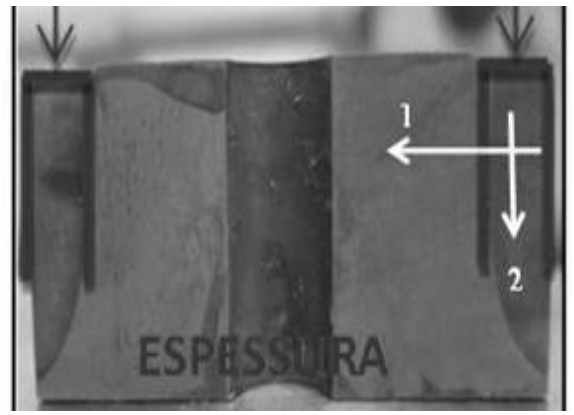

(b)

Figura 4: Corpo-de-prova retirado do virabrequim: (a) medição de espessura tratada termicamente e (b) Corpo de prova para medição metalografia, indicando a espessura temperada.

Em seguida, foi realizado o procedimento experimental para preparação dos corpos de provas, Figura 4(b), visando à revelação da microestrutura nas regiões compreendidas pelo núcleo e daquela representativa da camada tratada termicamente. Nessa etapa, técnicas tradicionais de metalografia foram aplicadas, as quais compreendem corte, embutimento, lixamento, polimento e ataque com reagente químico adequado. A revelação das microestruturas ocorreu mediante imersão das amostras (três, sendo uma para cada virabrequim) em uma solução aquosa de $5 \%$ de Nital ( $95 \mathrm{ml}$ de álcool etílico e $5 \mathrm{ml}$ de ácido nítrico concentrado)por um tempo de 30 segundos. AS imagens das microestruturas foram obtidas com auxílio do sistema de processamento de imagens Olympus, modelo UC30, acoplado ao software de captura de imagem Analise Sys.

Finalmente, uma das 3 (três) amostras foi utilizada para o ensaio de Difratometria de Raios X (DRX). A análise teve como premissa básica determinar as fases presentes nas microestruturas obtidas, após o tratamento térmico por indução eletromagnética. Os espectros foram obtidos através de um Difratômetro Shimadzu XRD-7000 e anodo de cobre $(\lambda=1,5406 \AA$ ) em um intervalo de 5 a 90 2Ө. Para a identificação das fases utilizou-se o programa X'Pert HighScore da PANalytical e a base de dados PDF2 do ICDD.

\section{RESULTADOS E DISCUSSÕES}

A Figura 5 apresenta, para dois virabrequins tratados termicamente, as microestruturas obtidas após a têmpera superficial por indução eletromagnética, aplicada neste trabalho. As 
Regiões 1, 2 e 3 representam, respectivamente: metal de base (MB) ou região que não sofreu tratamento térmico; região de transição entre $\mathrm{MB}$ e aquela que foi tratada termicamente e, finalmente; região que se submeteu ao tratamento térmico por têmpera por indução, respectivamente. Observa-se na Região 1, indicada por setas nas três (3) amostras analisadas, uma estrutura reticular composta de ferrita primária pró-eutetóide em rede nos contornos de grãos de perlita fina, apresentando em torno de 20 HRC. A microestrutura presente nesta região (Região 1), mostra que a mesma foi afetada pelo processamento térmico, aquecimento e posterior resfriamento, sem, no entanto, ter afetado a dureza.

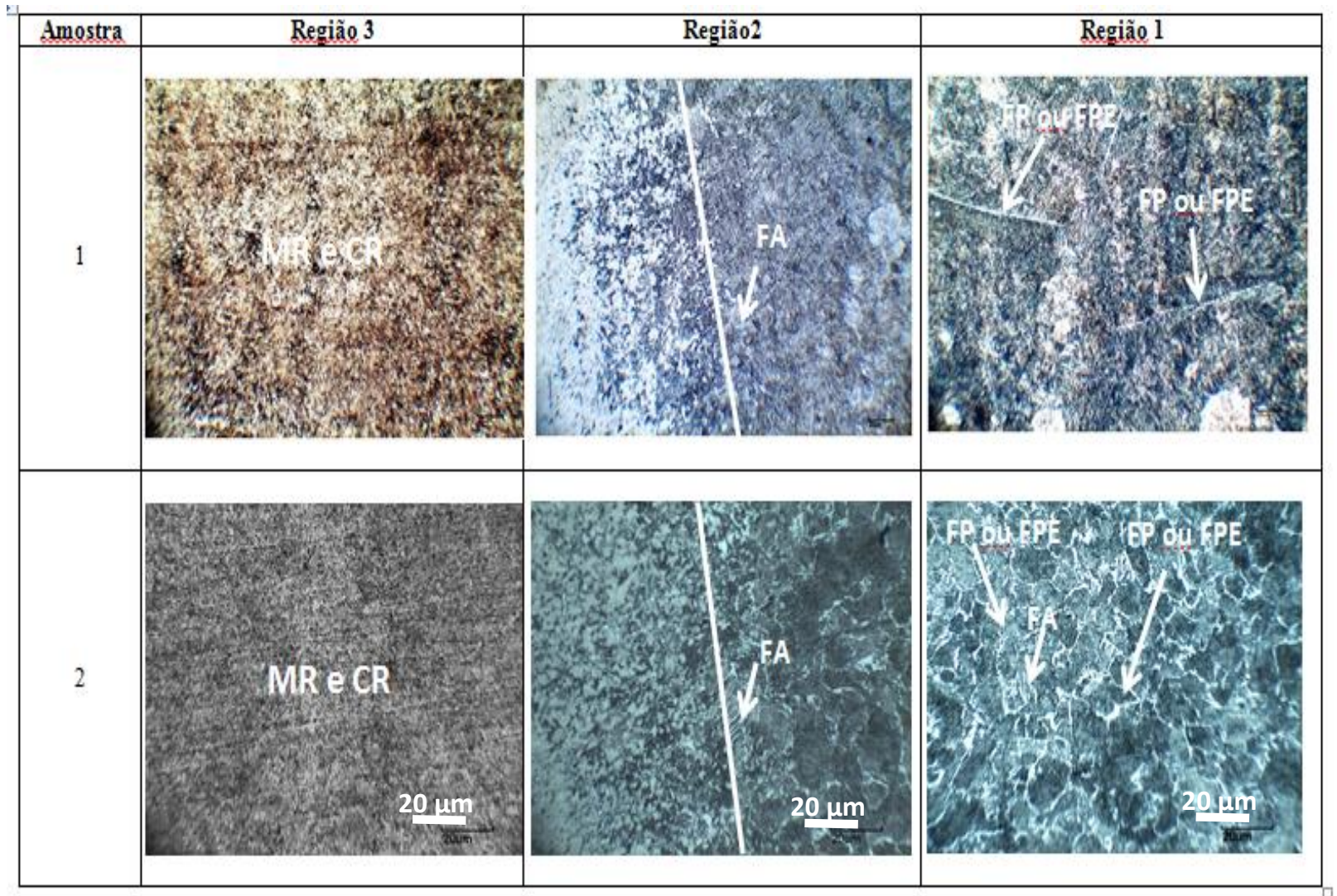

Figura 5: Microestruturas reveladas das três (3) peças retiradas do virabrequim, tratadas termicamente: Região 1 metal de base (MB) que não sofreu o tratamento térmico; Região 2 - transição entre o MB e a região tratada termicamente; Região 3 - tratada termicamente por têmpera por indução eletromagnética. (FP - ferrita primária; FPE - ferrita pro-eutétoide; FA - ferrita acicular; MR - matensita revenida; CR - carbonetos refinados).

As Figuras 6 e 7 representam, respectivamente, as microfotografias do MB da Peça 1, submetida ao tratamento térmico por indução eletromagnética, e da peça em estado não tratado termicamente (matéria prima - MP). Observa-se, portanto, pela Figura 6, a influência do tratamento térmico na formação da microestrutura. As regiões escuras da Figura 7 correspondem ao composto perlita e as regiões claras correspondem a uma fase primária ferrita (FP), provavelmente formadas por processamento térmico com reações por difusão, devido a resfriamentos lentos. 


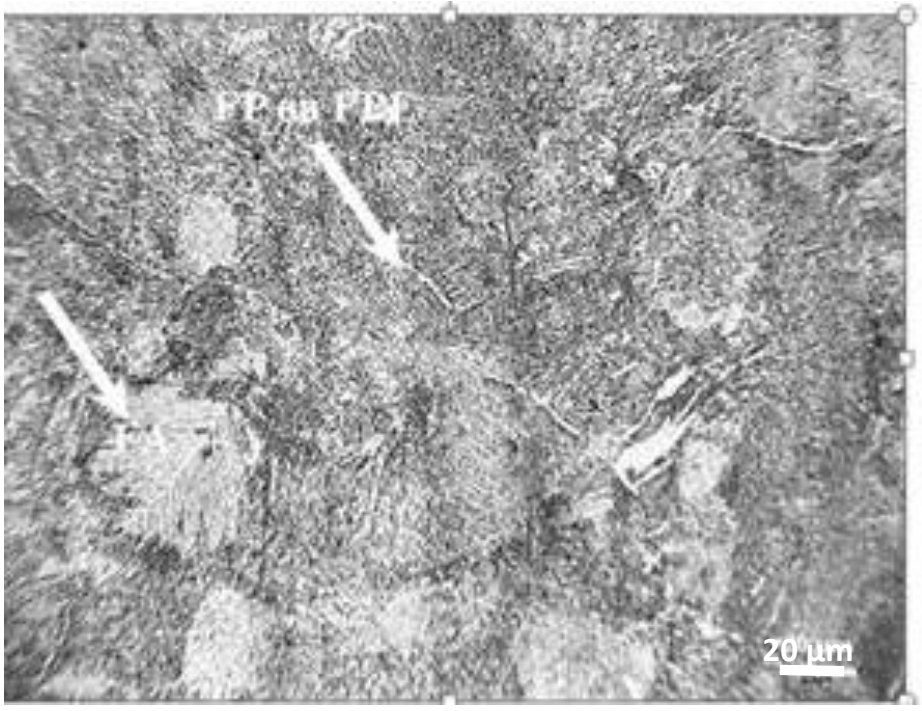

Figura 6: Microfotografia da Peça 1, obtida da Região 1 (núcleo), referente à peça tratada termicamente. Ferrita (FP - ferrita primária; FPE - ferrita pro-eutétoide; FA - ferrita acicular).

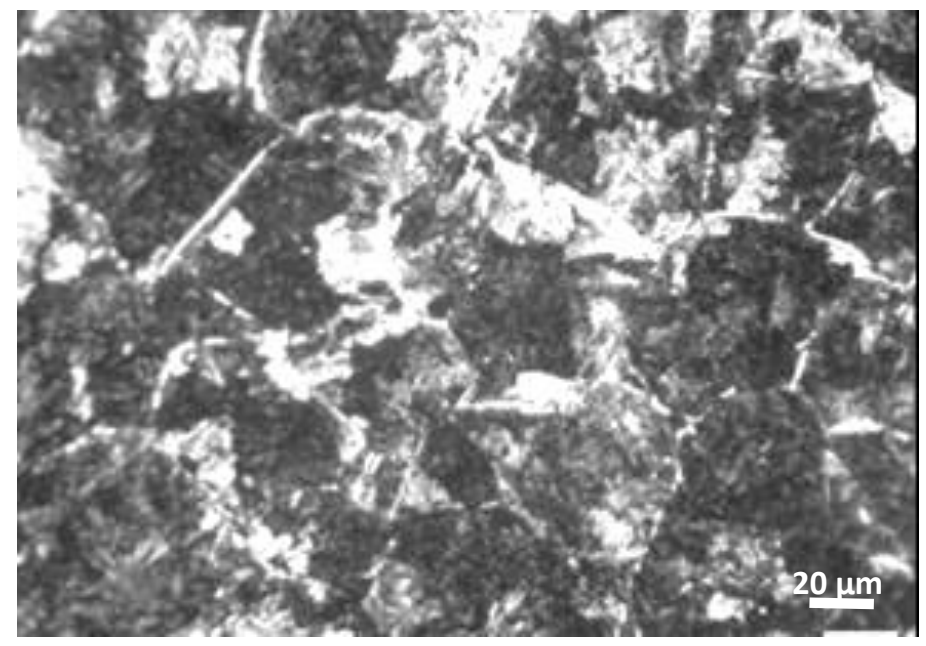

Figura 7: Microfotografia da peça não processada termicamente.

A Região 2, observada na Figura 5 , ou região de zona de transição, apresenta uma transição microestrutural a partir do MB para o interior da região tratada termicamente. Verifica-se uma microestrutura bastante refinada, composta de carbonetos metaestáveis em uma matriz predominantemente de ferrita refinada, provavelmente precipitados da martensita durante o processo de revenimento, que se estende até o interior da Região 3, resultando numa estrutura de elevada dureza, cerca de 54 HRC. A presença desses carbonetos e de ferrita refinada predomina-se, praticamente, em toda borda da região tratada, conforme verificado na Região 3 da Figura 5.

O revenido pós-têmpera, visa otimizar o par de propriedades "dureza" e "resistência ao choque", com vista a determinada aplicação, propriedades essas exigidas para componentes transmissores de potência, como o virabrequim de motocicletas (RUDNEV et al,1997; TASH et al, 2007; VENKATESH et al, 2009). Vale ressaltar que por motivo de segredo industrial não são apresentados no presente trabalho os resultados de ensaio de impacto (Ensaio Charpy). Venkatesh et al. (2009) explica que no revenimento a baixa temperatura, cerca de $200^{\circ} \mathrm{C}$, verifica-se a perda da tetragonalidade da martensita e entre $200^{\circ} \mathrm{C}$ e $300^{\circ} \mathrm{C}$ se observa que a austenita residual, 
presente no aço, decompõe-se em bainita e carbonetos. A natureza desses carbonetos não se encontra consolidado na literatura, havendo alguns autores que os identificam com a cementita e outros com o carboneto $\varepsilon$ (RUDNEV et al,1997; KRAUSS, 1990; LOVELESS et al, 2000). Entre $300^{\circ} \mathrm{C}$ e $500^{\circ} \mathrm{C}$, para alguns autores, o fenômeno inicia em $300^{\circ} \mathrm{C}$ (RUDNEV et al,1997; RUDNEV, 2003; 2004; SAHAA et al., 2010; VENKATESH et al, 2009), e os carbonetos de transição transformam-se em cementita, e a martensita de baixo carbono originará uma matriz ferrítica, com a simultânea rejeição do carbono em excesso.

A Figura 8 apresenta de forma ampliada a Região 3 da peça 1 que sofreu o tratamento de revenimento a $480^{\circ} \mathrm{C}$, após temperatura superficial por indução eletromagnética. Nota-se uma região composta de uma microestrutura conhecida como martensita-revenida (RUDNEV et al,1997; RUDNEV 2003; 2004; SAHAA et al, 2010; VENKATESH et al, 2009). Observa-se que a martensita, durante o revenimento, pela perda de sua tetragonalidade, transformou-se em carbonetos metaestáveis distribuídos em uma matriz predominantemente de ferrita refinada, compondo-se, portanto, numa estrutura completamente cubica de corpo centrado (CCC). A Figura 9 apresenta o resultado do ensaio por Difratometria de R-X (DRX) realizado na Região 3 da Peça 1 (Figura 5), mostrando como resultado uma estrutura predominante CCC.

A dureza HRC, bem como a profundidade da superfície tratada termicamente, foram medidas de acordo com as metodologias apresentadas. As Tabelas 3 a 5 apresentam os resultados obtidos para os três virabrequins tratados termicamente. Observa-se que os valores medidos se encontram entre os limites de tolerâncias especificados para o processo (Tabela 2), confirmando, portanto, a eficácia operacional do tratamento térmico de têmpera superficial por indução eletromagnética assumido neste trabalho.

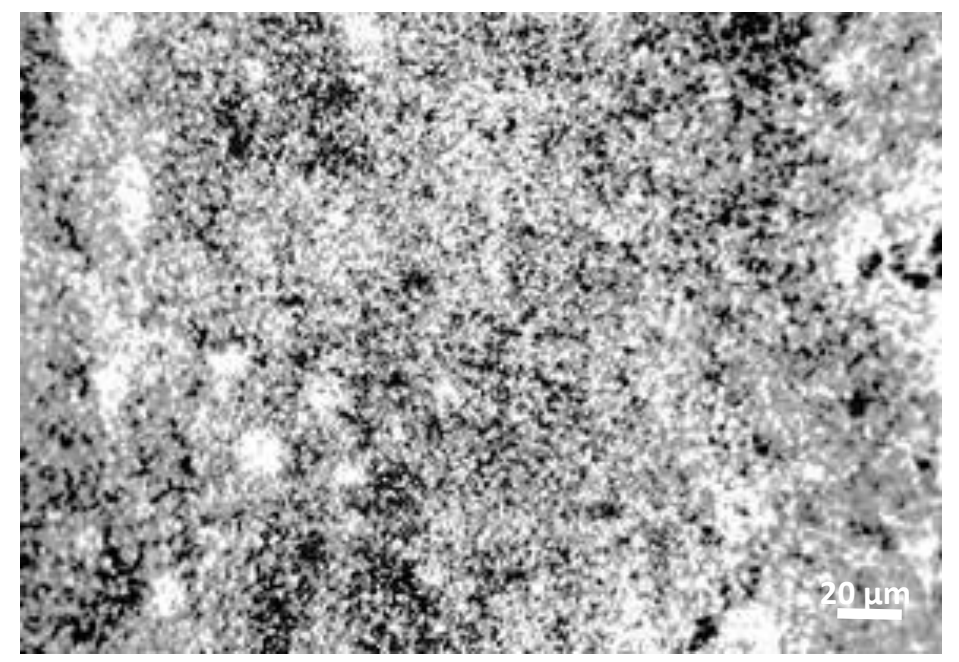

Figura 8: Microfotografia da Região 3 da Peça 1 (Figura 4) que sofreu o tratamento de revenimento a 4800C, após temperatura superficial por indução eletromagnética. 


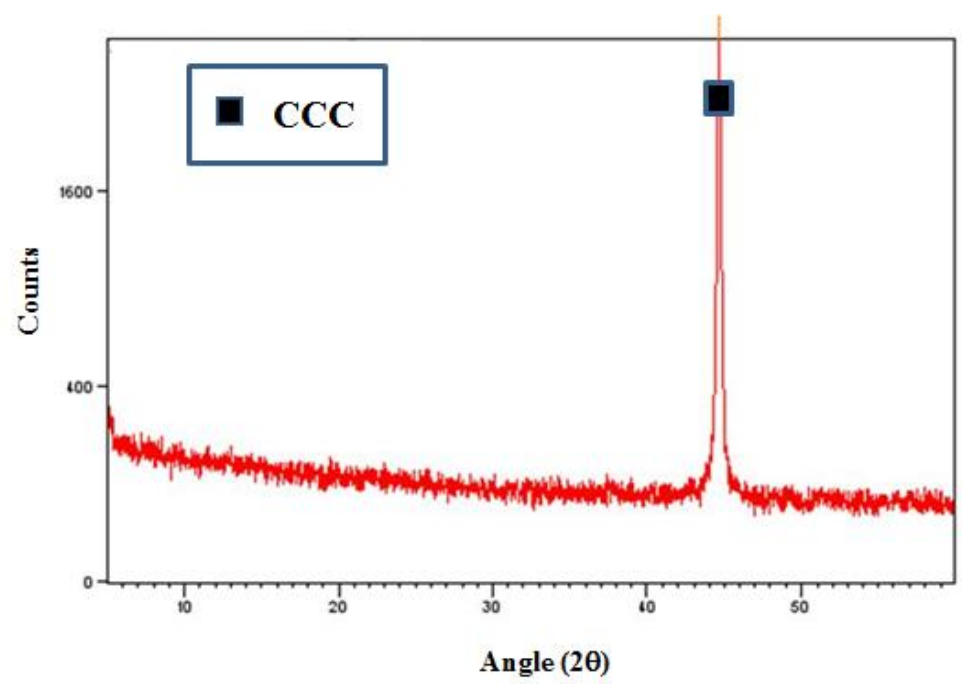

Figura 9: Difrações de raios X (DRX) da Região 3, Peça 1(Fig. 7).

Tabela 3: Resultados experimentais obtidos da profundidade e dureza do tratamento térmico - Virabrequim 1.

\begin{tabular}{|ccc}
\hline \multicolumn{1}{|c}{ Cota (Fig.1) } & Descrição & Encontrado \\
\hline A & Profundidade da têmpera (mm) & 1,5 \\
\hline C & Dureza a têmpera (HRC) & 54 \\
\hline D & Dureza do núcleo (HRC) & 20 \\
\hline
\end{tabular}

Tabela 4: Resultados experimentais obtidos da profundidade e dureza do tratamento térmico - Virabrequim 2.

\begin{tabular}{|ccc}
\hline Cota (Fig.1) & Descrição & Encontrado \\
\hline A & Profundidade da têmpera (mm) & 1,2 \\
\hline C & Dureza a têmpera (HRC) & 54 \\
\hline D & Dureza do núcleo (HRC) & 22 \\
\hline
\end{tabular}

Tabela 5: Resultados experimentais obtidos da profundidade e dureza do tratamento térmico - Virabrequim 3.

\begin{tabular}{|ccc}
\hline \multicolumn{1}{|c}{ Cota (Fig.1) } & Descrição & Encontrado \\
\hline A & Profundidade da têmpera (mm) & 1,5 \\
\hline C & Dureza a têmpera (HRC) & 58 \\
\hline D & Dureza do núcleo (HRC) & 23 \\
\hline
\end{tabular}

\section{CONCLUSÕES}

A análise dos resultados experimentais obtidos neste trabalho, relacionados à têmpera superficial por indução eletromagnética para três virabrequins direito de uma motocicleta, fabricados a partir do aço AISI 1045, permite que sejam extraídas as seguintes conclusões:

1. A microestrutura reticular observada na região central, embora afetada pelo tratamento térmico, mostrou a formação de ferrita pró-eutetóide em torno dos grãos anteriormente austenítico que formaram colônias de perlita fina, apresentando dureza de 20 HRC, atendendo os padrões estabelecidos;

2. A zona de transição começa a ocorrer a $1,5 \mathrm{~mm}$ da superfície tratada, quando aparece uma região apresentando microestrutura bastante refinada, constituída de carbonetos 
metaestáveis em uma matriz predominantemente de ferrita refinada, provavelmente precipitados da martensita durante o processo de revenimento, que se estende até o interior da região tratada térmicamente, resultando numa estrutura de elevada dureza, cerca de 55 HRC em média. A presença desses carbonetos e de ferrita refinada predominase, praticamente, em toda borda da região tratada. Foi possível observar a presença da estrutura metaestável martensítica muito refinada, mas com predominância de carbonetos refinados dispersos em muma matriz muito rica em ferrita e bastante refinada, resultando, portanto numa estrutura Martensita-Revenida;

3. O resultado de difratometria de Raio X (DRX) realizado em uma das peças, aponta uma estrutura predominante CCC, confirmando a presença de uma matriz rica em ferrita, e refinada.

4. Os resultados obtidos para a dureza mostram valores elevados na região tratada termicamente, resultando no valor médio entre os três virabrequins de 55 HRC.

\section{AGRADECIMENTOS}

Ao Instituto Federal de Educação, Ciência e Tecnologia do Pará (IFPA), ao ITEGAM/AM e ao Programa de Pós-Graduação de Engenharia Industrial (PPGEI) da Universidade Federal do Pará, pelo apoio de infraestrutura e financeiro, concedidos para a realização deste trabalho.

\section{REFERÊNCIAS BIBLIOGRÁFICAS}

1. DANDA, S. Effect of induction hardening on high carbon steel forgings. International Journal of Soft Computing and Engineering IJSCE v.1, p.15-18, 2011.

2. FERREIRA, C. R.; ARAÚJO, F. G. S.; OLIVEIRA, C. P; COTA, A. B. C. Tratamento térmico por indução eletromagnética em tubos de aço SAE 1045 para produção de hastes de sondagem geológica. Metalurgia \& Materiais v. 57(1), p. 23-26, 2004.

3. KANG, J., WANG, C., WANG, G. D., Microstructural characteristics and impact fracture behavior of a high-strength low-alloy steel treated by intercritical heat treatment. Materials Science and Engineering A, v. 553, p. 96-104, 2012.

4. MACEDO, Q. M. Efeito dos parâmetros de austenitização sobre a microestrutura e propriedades do Aço 4130 submetido a tratamentos térmicos por indução eletromagnética. Dissertação (Mestrado) - Programa de Pós-Graduação em Engenharia de Materiais da REDEMAT, Outro Preto, 2007.

5. RUDNEV, V. I., LOVELESS, D. L., COOK, R. L., BLACK, M. R. Induction heat treatment: basics principles, computation, coil construction, and design considerations, In: Totten, G. E., Howes, M. A. H. Steel Heat Treatment Handbook, M. New York: Dekker, p. 765-867, 1997.

6. RUDNEV,V. Can Fe-Fe3C phase transformation diagram be directly applied in induction hardening of steel? , Professor Induction Series, Heat Treating Progress, ASM Int., June/July. p.27, 2003.

7. RUDNEV, V. L; LOVELESS, D. L; COOK, R. L. e BLACK. M. R. Handbook of induction Heating. New York: Editora Mareei Dekker. p 11 - 136, 2003.

8. RUDNEV, V. Induction Heat Treating: The Basics \& Beyond. In: II Conferência Brasileira de Temas de Tramento Térmico, Atibaia, São Paulo, 2004. 
9. SAHAA, A., MONDALB, D. K., MAITYB, J. Effect of cyclic heat treatment on microstructure and mechanical properties of 0.6 wt\% carbon steel. Materials Science and Engineering A v. 527, p.4001-4007, 2010.

10. VENKATESH, B.D., CHEN, D.L., BHOLE, S.D., Effect of heat treatment on mechanical properties of Ti-6Al-4V ELI alloy. Materials Science and Engineering A, v. 506, p.117-124, 2009.

11. YUAN, J., KANG, J., RONG, Y., AND SISSON, R.D. Jr. FEM Modeling of Induction Hardening Processes in Steel. Journal of Materials Engineering and Performance. v.12, p. 89-596, 2003.

12. SHIVKUMAR, S., RICCI, S., KELLER, C. APELIAN, D. Effect of solution treatment parameters on tensile properties of cast aluminum alloys. Journal of Heat Treating, v.8, n.1, p. 63-70, 1990.

13. TASH, M., SAMUEL, F.H., MUCCIARDI, F., DOTY, H.W. Effect of metallurgical parameters on the hardness and microstructural characterization of as-cast and heat-treated 356 and 319 aluminum alloys. Materials Science and Engineering A, v.443, p. 185-201, 2007.

14. Totik, Y., Sadeler, R., Altun H., Gavgali M. The effects of induction hardening on wear properties of AISI 4140 steel in dry sliding conditions. Materials \& Design, v. 24, p.25-30, 2003

15. Blaow, M., Evans I. T., Shaw,B. A. The effect of microstructure and applied stress on magnetic Barkhausen emission in induction hardened steel. Journal of Materials Science, v. 42, p. 43644371, 2007.

16. Feng, L., Xuekun, L., Tianxing, Z., Qianzhe, Z., Yiming, K. R. Modeling and simulation of induction heating with magnetic flux concentrator. Applied Mechanics and Materials, v. 268270, p.983-991, 2013.

17. Barka N., Ouafi A. El., Bocher P., Brousseau, J.Explorative Study and Prediction of Overtempering Region of Disc Heated by Induction Process Using 2D Axisymmetric Model and Experimental Tests. Advanced Materials Research, v.268, p.259-265, 2012.

18. Barka N., hebak, A., Ouafi A. El., Jahazi, M., Menou A. A New Approach in Optimizing the Induction Heating Process Using Flux Concentrators: Application to 4340 Steel Spur Gear. Journal of Materials Engineering and Performance, v.23, p. 3092-3099, 2014. 